\title{
Kepemimpinan Religius Bhikkhu di Sekolah Tinggi Agama Buddha
}

\author{
Sigit Budiyanto ${ }^{1}$, Ibrahim Bafadal ${ }^{1}$, Burhanuddin ${ }^{1}$ \\ ${ }^{1}$ Manajemen Pendidikan-Universitas Negeri Malang
}

\begin{tabular}{l}
\hline INFO ARTIKEL \\
\hline Riwayat Artikel: \\
Diterima: $18-02-2020$ \\
Disetujui: $20-07-2020$ \\
\hline
\end{tabular}

Kata kunci:

bhikkhu leadership;

religious value;

Buddhist;

kepemimpinan bhikkhu;

nilai religius;

agama buddha

\begin{abstract}
ABSTRAK
Abstract: This research was conducted using a qualitative approach with a multi-site study design. This research was conducted at Kertaraja Buddhist College in Batu and Smaratungga Buddhist College in Ampel. This study aims to explain (1) religious values that inspire the leadership of monks in Buddhist educational institutions, (2) the type of monk's leadership in Buddhist educational institutions, (3) the principles of monk's leadership in Buddhist education institutions. The results of this study are as follows: first, internal encouragement in the form of experience as a leader and encouragement to serve and meet academic qualifications, while external encouragement is basically appointed by the foundation to become chairman. Religious values in the leadership of monks in higher education institutions of Buddhism are values contained in the dasa raja dhamma. Second, the type of monk leadership in Buddhist religious education institutions is mixed, namely: democratic type, delegate leadership behavior and participative leadership. The way the head of higher education involves members to achieve organizational goals is by placing the right people, giving the vice chairman a big role and active participation of members. A personal figure as a monk who is a Buddhist clergyman and uses a humanistic approach, as well as an element of kinship in work culture. Third, the use of communication tools by the Head of the Buddhist College when not in place.
\end{abstract}

\begin{abstract}
Abstrak: Penelitian ini dilakukan dengan menggunakan pendekatan kualitatif dengan rancangan studi multi situs. Penelitian ini dilakukan di STAB Kertaraja Batu dan STIAB Smaratungga Ampel. Penelitian ini bertujuan menjelaskan (1) nilai religius yang menjiwai kepemimpinan bhikkhu di lembaga pendidikan agama Buddha, (2) jenis kepemimpinan bhikkhu di lembaga pendidikan agama Buddha, (3) prinsip kepemimpinan bhikkhu di lembaga pendidikan agama Buddha. Hasil penelitian ini adalah sebagai berikut. Pertama, yaitu dorongan internal berupa pengalaman sebagai pemimpin dan dorongan untuk mengabdi dan memenuhi syarat kualifikasi akademik, sedangkan dorongan eksternal yaitu pada dasarnya ditunjuk oleh yayasan untuk menjadi ketua. Nilai religius dalam kepemimpinan bhikkhu di lembaga pendidikan tinggi agama Buddha yaitu nilai yang termuat dalam dasa raja dhamma. Kedua, jenis kepemimpinan bhikkhu di lembaga pendidikan agama Buddha mix (campuran), yaitu tipe demokratis, perilaku kepemimpinan delegasi dan partisipatif. Cara ketua perguruan tinggi dalam melibatkan anggota untuk mencapai tujuan organisasi yaitu dengan melakukan penempatan orang yang tepat, memberikan peran besar wakil ketua dan partisipasi aktif anggota. Sosok personal sebagai bhikkhu yang merupakan rohaniawan buddhis dan menggunakan pendekatan humanistik, serta unsur kekeluargaan dalam budaya kerja. Ketiga, penggunaan alat komunikasi oleh Ketua Sekolah Tinggi Agama Buddha ketika tidak berada di tempat.
\end{abstract}

\author{
Alamat Korespondensi: \\ Sigit Budiyanto \\ Manajemen Pendidikan \\ Universitas Negeri Malang \\ Jalan Semarang 5 Malang \\ E-mail: sigitbudiyanto15@gmail.com
}

Sesuai dengan tujuan pendidikan yang tertuang dalam Undang-Undang Sistem Pendidikan Nasional Nomor 20 Tahun 2003 Bab 2 Pasal 3 adalah Pendidikan Nasional berfungsi mengembangkan kemampuan dan membentuk watak serta peradaban bangsa yang bermartabat dalam rangka mencerdaskan kehidupan bangsa, bertujuan untuk berkembangnya potensi peserta didik agar menjadi manusia yang beriman, dan bertakwa kepada Tuhan Yang Maha Esa, berakhlak mulia, sehat, berilmu, cakap, kreatif, mandiri, dan menjadi warga negara yang demokratis serta bertanggungjawab. Pada penelitian ini, peneliti mengambil situs penelitian di Sekolah Tinggi Agama Buddha Kertarajasa dan Sekolah Tinggi Ilmu Agama Buddha Smaratungga. Berdasarkan observasi awal yang dilakukan oleh peneliti bahwa faktor sosok pemimpin yang melatarbelakangi peneliti untuk mengambil 
kedua situs tersebut. Ketua dari masing-masing situs tersebut adalah bhikkhu seorang pemuka Agama Buddha. Hal itu oleh peneliti dijadikan sebagai dasar pertimbangan yang menjadi keunikan penentuan kedua situs yang dipilih. Dari sekian banyak perguruan tinggi Agama Buddha, hanya STAB Kertarajasa yang berada di provinsi Jawa Timur dengan ciri mazhab Theravāda. Istilah Theravāda, yang secara harfiah berarti 'doktrin para tetua', menyampaikan arti tradisi 'paling awal', 'tertua' atau 'murni' (Crosby et al., 2014).

STAB Kertarajasa juga merupakan suatu organisasi di bidang pendidikan yang menetapkan seorang bhikkhu aliran Theravāda dalam menjabat sebagai pemimpin lembaga. STAB Kertarajasa yang diketuai oleh seorang bhikkhu yaitu Bhikkhu Subhapañño Subanowo, S.H., M.M merupakan anggota Sañgha Theravāda Indonesia (STI). Sementara itu, di situs yang kedua, STIAB Smaratungga juga menetapkan seorang bhikkhu tradisi Theravāda yang tergabung dalam mahzab Buddhayana, sosok bhikkhu menjabat pimpinan lembaga tersebut yaitu Bhikkhu Dițhisampanno, M.A., merupakan anggota Sangha Agung Indonesia. Sebagaimana yang telah diketahui masyarakat buddhis bahwa bhikkhu adalah guru spiritual bagi umat Buddha. Namun, di STAB terdapat seorang bhikkhu yang tidak hanya menjadi guru spiritual, tetapi juga menjabat sebagi ketua lembaga pendidikan. Sebagai seorang figur yang menjadi panutan sekaligus pembabar ajaran agama Buddha, seorang bhikkhu memiliki banyak umat yang menyebar di seluruh Indonesia. Hal ini memungkinkan terjadinya interaksi positif yang membuat umat Buddha dan masyarakat luas di berbagai daerah mengenal STAB Kertarajasa dan STIAB Smaratungga.

\section{METODE}

Penelitian ini dilakukan dengan menggunakan pendekatan kualitatif dengan rancangan studi multi situs. Pendekatan yang digunakan dalam penelitian ini adalah kualitatif deskriptif, dimana peneliti lebih menekankan pada pengungkapan makna dan proses dengan latar belakang alami sebagai sumber data langsung (Moleong, 2014). Penelitian ini dilakukan di STAB Kertarajasa Batu dan STIAB Smaratungga Ampel.

Tabel 1. Persamaan Karakteristik Situs I dan Situs II

\begin{tabular}{|c|c|c|c|}
\hline No & Aspek & STAB Kertarajasa & STAB Smaatungga \\
\hline 1. & Status Perguruan Tinggi & Perguruan Tinggi Swasta & Perguruan Tinggi Swasta \\
\hline 2. & Ketua Perguruan Tinggi & Bhikkhu (rohaniawan Buddha) & Bhikkhu (rohaniawan Buddha) \\
\hline 3. & Penyelenggara Pendidikan & Di bawah naungan yayasan & Di bawah naungan yayasan \\
\hline 4. & Sumber Biaya & Peserta didik \& yayasan & Peserta didik \& yayasan \\
\hline 5. & Hari Pembelajaran Efektif & Senin_-Jum'at & Senin_-Jum'at \\
\hline 6. & Peserta didik & $\begin{array}{l}\text { Terdapat biarawan (sāmaṇera) dan biarawati } \\
\text { (atṭhasīlani) }\end{array}$ & $\begin{array}{l}\text { Terdapat biarawan (sāmaṇera) dan biarawati } \\
\text { (sāmaṇeri) }\end{array}$ \\
\hline 7. & Naungan Mahzab & $\begin{array}{l}\text { STAB swasta yang berbasis bhikkhu tradisi } \\
\text { Theravāda }\end{array}$ & $\begin{array}{l}\text { STAB swasta yang berbasis bhikkhu tradisi } \\
\text { Theravāda }\end{array}$ \\
\hline 8. & Lokasi & Berada di komplek vihara & Berada di komplek vihara \\
\hline
\end{tabular}

Tabel 2. Profil Sekolah Tinggi Agama Buddha Kertarajasa

\begin{tabular}{lll}
\hline 1. Nama Perguruan Tinggi & Sekolah Tinggi Agama Buddha (STAB) Kertarajasa \\
2. Tahun Berdiri & 9 Oktober 2000 \\
3. Alamat Perguruan Tinggi & J1. Ir. Soekarno No. 311, Kota Batu (65322), Jawa Timur \\
4. Izin Operasional & H/69/SK/2000 \\
5. Nama Yayasan & Yayasan Dhammadipa Arama \\
\hline
\end{tabular}


Tabel 3. Profil Sekolah Tinggi Ilmu Agama Buddha Smaratungga

\begin{tabular}{lll}
\hline 1. & Nama Perguruan Tinggi & Sekolah Tinggi Ilmu Agama Buddha (STIAB) Smaratungga \\
2. & Tahun Berdiri & 1 September 1986 \\
3. & Alamat Perguruan Tinggi & Jl. Semarang-Solo Km. 60, Ampel, Boyolali kode pos 57352, Provinsi Jawa Tengah. \\
4. & Izin Operasional & $\mathrm{H} / 15 / \mathrm{SK} / 1989$ \\
5. & Nama Yayasan & Yayasan Buddhayana Semarang \\
\hline
\end{tabular}

Pengumpulan data dalam penelitian ini dilakukan dengan teknik wawancara mendalam, observasi, dan studi dokumentasi. Analisis data dilakukan dalam dua tahapan, yaitu analisis data situs individu dan analisis data lintas situs. Menurut Miles et al (2014) analisis data terdiri dari kegiatan yang dapat dilakukan secara bersama-sama, yaitu (a) kondensasi data, (b) penyajian data, dan (c) penarikan kesimpulan. Pengecekan keabsahan data dilakukan agar data yang diperoleh tidak diragukan kebenarannya. Temuan penelitian dinyatakan dapat dipercaya apabila tidak ada perbedaan yang dilaporkan peneliti dengan apa yang sesungguhnya terjadi. Akan tetapi, kebenaran menurut penelitian kualitatif bersifat jamak tergantung proses mental tiap individu dengan berbagai latar penelitian. Oleh karena itu, dalam penelitian kualitatif perlu dilakukan uji keabsahan data (Lincoln \& Guba, 1985). Peneliti melakukan tiga pengecekan keabsahan data, yaitu kreadibilitas, transfermabilitas, dan konfirmabilitas.

\section{HASIL}

Hasil temuan akhir dalam penelitian ini dijabarkan berdasarkan fokus penelitian, yaitu (1) nilai religius yang menjiwai kepemimpinan bhikkhu (2) jenis kepemimpinan bhikkhu di lembaga pendidikan agama Buddha, (3) prinsip kepemimpinan bhikkhu di lembaga pendidikan agama Buddha.

Tabel 4. Hasil Temuan Lintas Situs

\begin{tabular}{|c|c|c|}
\hline \multicolumn{3}{|c|}{ Kepemimpinan Religus Bhikkhu di Sekolah Tinggi Agama Buddha } \\
\hline Nilai Religius Kepemimpinan Bhikkhu & Jenis Kepemimpinan Bhikkhu & Prinsip Kepemimpinan Bhikkhu \\
\hline $\begin{array}{l}\text { Dorongan ketua STAB: memenuhi syarat } \\
\text { kualifikasi akademik, pengalaman sebagai } \\
\text { pemimpin dan dorongan untuk mengabdi yang } \\
\text { pada dasarnya ditunjuk oleh yayasan untuk } \\
\text { menjadi ketua. }\end{array}$ & $\begin{array}{l}\text { Jenis kepemimpinan Bhikkhu: tipe } \\
\text { demokratis, perilaku kepemimpinan } \\
\text { delegasi, dan partisipatif. Memberikan } \\
\text { dampak pada lemah dibagian kontrol dan } \\
\text { sulit dalam mengambil keputusan. }\end{array}$ & $\begin{array}{l}\text { Dalam membangun komunikasi: penggunaan } \\
\text { alat komunikasi ketika tidak berada di } \\
\text { tempat, mudah dihubungi serta pola } \\
\text { komunikasi formal dan non formal } \\
\text { tergantung dari situasi. }\end{array}$ \\
\hline \multirow[t]{2}{*}{$\begin{array}{l}\text { Nilai-nilai religius dalam kepemimpinan } \\
\text { bhikkhu: Dasa raja dhamma merupakan nilai } \\
\text { religius yang terdapat dalam diri ketua yang } \\
\text { dalam pelaksanaannya ditunjang oleh } \\
\text { pengendalian diri sesuai dhamma vinaya dan } \\
\text { pelaksanaan meditasi. }\end{array}$} & $\begin{array}{l}\text { Pelibatan anggota dalam mewujudkan } \\
\text { tujuan organisasi: melakukan penempatan } \\
\text { orang yang tepat, memberikan peran besar } \\
\text { wakil ketua dan partisipasi aktif anggota. }\end{array}$ & $\begin{array}{l}\text { Penerapan kepemimpinan yang efektif dan } \\
\text { efisien: memberikan kontrol, memotivasi dari } \\
\text { jauh, serta memberikan wewenang kepada } \\
\text { wakil ketua. Pengambilan keputusan yang } \\
\text { cepat dan rapat untuk menyelasaikan } \\
\text { masalah. }\end{array}$ \\
\hline & $\begin{array}{l}\text { Menanamkan pengaruh terhadap anggota: } \\
\text { sosok personal sebagai bhikkhu yang } \\
\text { merupakan rohaniawan buddhis dan } \\
\text { menggunakan pendekatan humanistik, } \\
\text { serta unsur kekeluargaan dalam budaya } \\
\text { kerja. }\end{array}$ & $\begin{array}{l}\text { Dalam penyelesaian masalah: mengambil } \\
\text { sikap hati-hati dan tidak memihak, } \\
\text { melakukan pendekatan personal dengan } \\
\text { menerima masukan dari berbagai pihak. }\end{array}$ \\
\hline
\end{tabular}

\section{PEMBAHASAN}

Pada bagian ini berturut-turut disajikan pembahasan terhadap temuan penelitian yang dikelompokan menjadi tiga jabaran fokus, yaitu (1) nilai religius yang menjiwai kepemimpinan bhikkhu, (2) jenis kepemimpinan bhikkhu, (3) prinsip kepemimpinan bhikkhu di lembaga pendidikan tinggi agama Buddha. Berikut merupakan paparan selengkapnya dari pembahasan tersebut. 


\section{Nilai Religius yang Menjiwai Kepemimpinan Bhikkhu di Lembaga Pendidikan Agama Buddha}

Terdapat dua komponen pada fokus penelitian tentang nilai religius yang menjiwai kepemimpinan bhikkhu di lembaga pendidikan tinggi agama Buddha. Komponen tersebut yaitu dorongan bhikkhu menjadi ketua STAB (Sekolah Tinggi Agama Buddha), dan nilai-nilai religius yang menjiwai kepemimpinan bhikkhu di lembaga pendidikan tinggi agama Buddha. Faktor yang mendorong bhikkhu menjadi ketua di lembaga pendidikan tinggi agama Buddha dalam kedua situs yang diteliti ditemukan bahwa memiliki syarat kualifikasi akademik untuk menjabat sebagai ketua. Keberadaan bhikkhu sebelum menjadi ketua di lingkungan sekolah tinggi agama Buddha di tempat masing-masing pernah menjadi dosen dan mengajar di lembaga pendidikannya masing-masing. Faktor tersebut sesuai dengan yang diamanatkan dalam lampiran penjelasan yang terdapat pada peraturan menteri riset, teknologi, dan pendidikan tinggi Republik Indonesia, nomor 16 tahun 2018 tentang pedoman tata cara penyusunan statuta perguruan tinggi swasta yang dijelaskan bahwa pengaturan pengangkatan dan penetapan pemimpin PTS (Rektor/Ketua/Direktur) yaitu Senat Perguruan Tinggi melakukan seleksi calon pemimpin PTS (Rektor/Ketua/Direktur) dari kalangan dosen PTS, yang paling mampu memimpin PTS untuk mencapai visi dan target pengembangan PTS selama lima tahun sebagaimana tercantum dalam renstra yang telah ditetapkan oleh Badan Penyelenggara.

Menurut hasil penelitian yang dilakukan oleh (McKenzie, 2014) bahwa hasil menunjukkan korelasi positif antara persepsi perilaku pemimpin yang melayani dan kepuasan kerja guru di sekolah umum. Implikasi untuk kepemimpinan pendidikan termasuk mengembangkan kepala sekolah yang berpikiran melayani yang dapat membangun iklim yang berorientasi pada pelayan dalam sistem pendidikan publik. Pemimpin pendidikan harus seorang yang terpelajar untuk membangun dan mempertahankan pengalaman pendidikan yang relevan dan bermanfaat bagi peserta didik (Brooks \& Normore, 2010). Lebih lanjut, terdapat faktor internal yang menjadi dorongan bagi masing-masing ketua, yaitu keinginan untuk mengabdi (mendedikasikan diri/pelayanan) pada perguruan tinggi agama Buddha. Karakteristik dari sekolah tinggi agama Buddha yang didalamnya terdapat mahasiswa rohaniawan buddhis, baik laki-laki maupun perempuan juga menjadikan alasan penunjukan sosok bhikkhu untuk menjabat sebagai ketua. Beberapa tradisi agama lain memiliki 'virtuosi' seperti biarawan, biarawati, dan 'orang suci' yang menjalankan kepemimpinan berdasarkan kekuatan disiplin mereka, asketisme, pengabdian, dan tidak mementingkan diri sendiri. Sebagai contoh, san்gha, atau komunitas biara, tetap menjadi jantung agama Buddha di banyak bagian dunia (Beckford, 2015). Kemampuan managerial yang dimiliki oleh masing-masing ketua di kedua situs tersebut juga menjadi bagian dari faktor internal.

Nilai-nilai religius kepemimpinan bhikkhu dalam agama Buddha yang diimpelementasikan oleh ketua merupakan nilainilai yang tercantum dalam dasa raja dhamma. Dasa raja dhamma berisi pedoman untuk menjadi seorang pemimpin yang bijaksana. Menghafal isi Dasa Raja Dhamma tidak cukup untuk mengubah sikap seseorang. Pedoman ini perlu direnungkan secara mendalam, dilatih dengan jujur dan dilaksanakan dengan kewaspadaan sehingga terbentuk sikap batin yang baik sebagai pemimpin. Lebih lanjut, penjelasan tentang dasa raja dhamma yang disampaikan oleh Widya (2010) menyatakan bahwa dasa raja dhamma yang dimuat dalam Kitab Jataka merupakan asas kepemimpinan atau sepuluh kewajiban raja agar dapat memerintah dengan baik demi kesejahteraan rakyat (1) dana yaitu, kerelaan memberikan kepada mereka yang memerlukan, (2)

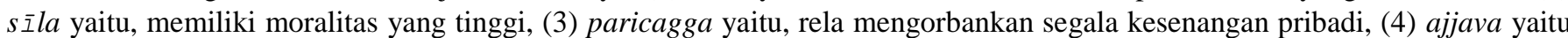
sikap jujur dan bersih, (5) maddava yaitu, sikap ramah, (6) tapa yaitu sikap pengendalian diri, (7) akkodha yang berarti bebas dari kebencian, (8) avihimsa yakni sikap tanpa kekerasan, (9) khanti yaitu sabar dan rendah hati, (10) avirodha yaitu tidak menentang atau bermusuhan. Nyanissara (2008) menyampaikan bahwa para pemimpin agama yang saat ini sedang atau akan melakukan pekerjaan sosial dan keagamaan, harus memberkahi diri dengan kualitas-kualitas mulia, seperti pelepasan keduniawian, atau pelepasan demi keuntungan pribadi, kebaikan cinta atau tanpa kebencian, tanpa permusuhan, serta tanpa kekerasan.

Implementasi nilai religius tersebut dalam kesehariannya dilakukan melalui perilaku, ucapan dan pikiran secara berkesinambungan. Kearifan pribadi merupakan atribut penting dari para pemimpin dalam organisasi keagamaan. Oleh karena itu, menekankan kebutuhan manusia akan spiritualitas penting dalam membuat penilaian yang baik dan rasa belas kasih kepada orang lain (Zacher et al., 2014). Hal lainnya juga karena sosok ketua sekolah tinggi agama Buddha merupakan sosok rohaniawan buddhis yaitu bhikkhu. Dalam perilaku dan ucapan, mereka diikat oleh 227 peraturan/vinaya kebhikkhuan (patimokha). Peraturan vinaya ditulis sebagai tindakan pencegahan terhadap potensi kritik di masa depan dan bentrok dengan masyarakat (Kaplan, 2016). Menurut hasil penelitian yang dilakukan oleh Gieseke (2014) bahwa ada hubungan positif yang signifikan secara statistik antara kecerdasan spiritual, mindfulness, dan kepemimpinan transformasional. Temuan ini dapat membantu pemimpin pendidikan tinggi publik merekrut, memperkerjakan, mempromosikan, melatih, dan mengembangkan pemimpin masa depan dengan cara yang lebih lengkap, holistik, dan efektif.

Ketua sekolah tinggi agama Buddha dalam praktik dasa raja dhamma ditunjang dengan pelaksanaan dhamma vinaya yang diajarkan oleh Buddha. Dipaparkan oleh Visuddhangkoon (2018) bahwa vinaya bukan hanya seperangkat kode yang harus diikuti secara mekanis dalam kehidupan monastik, melainkan hubungan pemersatu antara para bhikkhu dengan dhamma vinaya, kehidupan monastik dengan kehidupan monastik, dan kehidupan monastik dengan para perumahtangga, di atas landasan solidaritas spiritual dan ikatan persatuan, serta sangat toleran dan tidak memaksakan. 


\section{Jenis Kepemimpinan Bhikkhu di Lembaga Pendidikan Agama Buddha}

Pada fokus jenis kepemimpinan bhikkhu di lembaga pendidikan agama Buddha dijabarkan menjadi tiga komponen, yaitu jenis kepemimpinan bhikkhu, pelibatan anggota dalam mewujudkan tujuan organisasi, serta menanamkan pengaruh terhadap anggota. Menurut Hartog, Deanne N. Den \& Koopman (2001) menjelaskan bahwa tren kedua yang utama dalam meneliti kepemimpinan menekankan perilaku pemimpin. Fokus itu bergeser dari siapa pemimpin menjadi mengarah pada apa yang dilakukan pemimpin (gaya perilaku). Di dalam pendekatannya, efektivitas pemimpin tergantung pada perilaku kepemimpinan yang diberikan. Sementara itu, pendekatan sifat difokuskan pada karakteristik pribadi yang stabil biasanya dianggap sebagian besar bawaan (menyiratkan pemilihan pemimpin yang efektif daripada pelatihan), pendekatan gaya, menyiratkan bahwa kepemimpinan adalah pola perilaku yang dapat dipelajari. Jadi, menurut pendekatan ini, sekali seseorang dapat menemukan gaya 'benar', orang dapat dilatih untuk menunjukkan perilaku itu dan menjadi pemimpin yang lebih baik. Menurut Phipps (2012) gaya kepemimpinan tertentu yang diadopsi dan dipraktikkan oleh seorang pemimpin akan memoderasi sejauh mana keyakinan spiritual seseorang dapat memengaruhi pengambilan keputusan strategis. Pemeriksaan dengan seksama tentang cara-cara di mana setiap gaya kepemimpinan tertentu dapat memoderasi pengaruh di luar lingkup pekerjaan tersebut. Namun, dalam arti tertentu bukan gaya yang memoderasi pengaruh, melainkan kumpulan perilaku yang dicirikan dalam gaya kepemimpinan itu. Jenis kepemimpinan bhikkhu dalam lembaga pendidikan tinggi agama Buddha pada kedua situs diperoleh data bahwa tidak ada perilaku kepemipinan tunggal yang diterapkan. Terdapat perilaku kepemimpinan mix (campuran) dalam kepemimpinan di kedua lembaga tersebut. Perilaku kepemimpinan bhikkhu yang dipraktikan berupa delegasi dan partisipasif. Hal tersebut terjadi dikarenakan bahwa keberadaan ketua di kedua situs tidak selalu berada di lokasi. Pada situs pertama, Bhikkhu Subhapañño datang secara berkala dan kegiatan pengelolaan operasional didelegasikan kepada wakil ketua yaitu Pak Ary sehingga dari perilaku delegasi ini munculah partisipatif dari wakil ketua. Demikian pula yang terjadi pada situs kedua, Bhante Ditthisampanno sebagai Ketua di STIAB Smaratungga juga sedang melaksanakan studi doktoralnya sehingga hal tersebut menyebabkan beliau tidak selalu berada di tempat, dan kegiatan operasional lembaga didelegasikan kepada wakil ketua, yaitu Bu Suyati. Pola yang sama ditemukan dan terjadi pada kedua situs, dari delegasi menimbulkan partisipatif anggota. Kepemimpinan menjadi penentu utama terjadinya proses dinamisasi pendidikan. Pemimpin pendidikan menjadi unsur yang sangat penting bagi berlangsungnya dinamisasi pendidikan (Rohmat, 2010).

Menurut Hersey and Blanchard's $(1969,1977)$ dalam (Hartog, Deanne N. Den \& Koopman, 2001) tentang Situational Leadership Theory (SLT) menyatakan bahwa awalnya SLT (Situational Leadership Theory) mengusulkan para pemimpin harus menyesuaikan perilaku mereka agar sesuai dengan 'maturity'. 'development level ' tim secara keseluruhan serta anggota perorangan. Menggabungkan tugas tinggi dan rendah dan perilaku hubungan menciptakan empat kepemimpinan yang berbeda gaya, yaitu telling/instruksi (tugas tinggi, hubungan rendah); selling/konsultasi (tinggi, tinggi); participating (tugas rendah, tinggi hubungan); delegating (rendah, rendah).

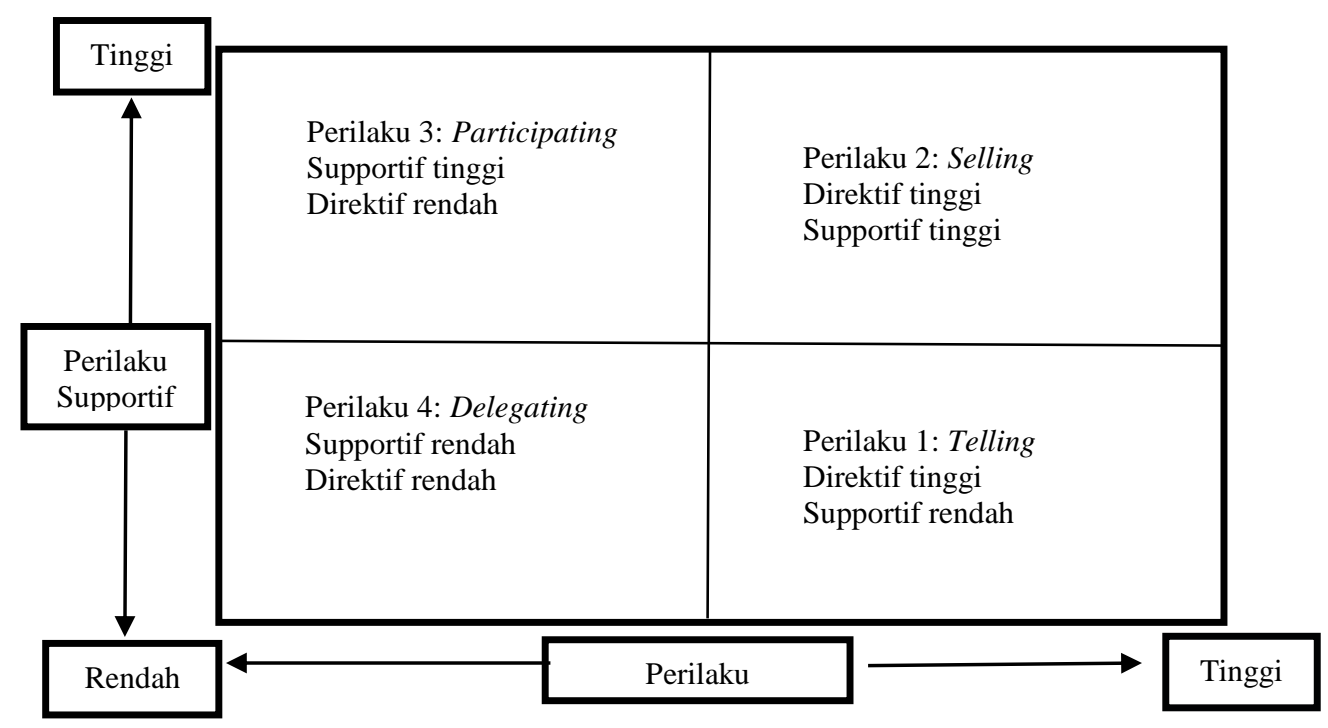

Gambar 1. Diagram Gaya Kepemimpinan Direktif dan Suportif 
Jenis kepemimpinan yang diterapkan oleh Ketua Sekolah Tinggi Agama Buddha menerapkan perilaku kepemimpinan delegasi dan partisipatif. Seperti dalam diagram di atas, penerapan perilaku kepemimpinan delegasi yaitu pemimpin tidak memberikan banyak pengarahan dan support karena sesuai unjuk kemampuan dan kemauan yang ditunjukan para tenaga kependidikan, maka pemimpin dapat memberikan tanggung jawab sepenuhnya kepada tenaga kependidikan untuk mengatasi dan menyelesaikan tugas-tugas/permasalahan yang diserahkan kepada tenaga kependidikan. Sedangkan perilaku kepemimpinan partisipatif yaitu pemimpin mendorong tenaga kependidikan menggunakan kemampuan yang dimiliki secara optimal. Seiring dengan kemampuan yang ditunjukan oleh tenaga kependidikan, pemimpin lebih banyak bertukar pendekatan dan memberikan kesempatan kepada mereka untuk mengambil keputusan. Studi kepemimpinan yang dilakukan di Ohio State University oleh Hempill \& Coons lalu kemudian diteruskan oleh Halpin \& Winner dalam (Riduwan, 2011) terdapat dua dimensi perilaku pemimpin yaitu struktur tugas dan tenggang rasa. Dari hasil penelitian lintas situs, ketua menerapkan perilaku delegasi dan partisipatif memiliki tujuan yaitu agar para anggotanya memiliki tanggung jawab dan inovasi sehingga tidak ada ketergantungan dengan ketua. Namun, dengan perilaku kepemimpinan delegasi dan partisipatif yang diterapkan itu, terdapat kelemahan dalam praktiknya, yaitu menyebabkan less direction, less supervision dan planing how to achieve the vision juga lemah. Selain itu, terdapat kelemahan lainnya yaitu jika hendak mengadakan rapat dan tidak ada sosok pemimpin, maka keputusan akan sulit diambil.

Menurut Imron (2017) dalam penggolongan yang paling klasik, paling tidak ada empat tipe kepemimpinan, yaitu (1) kepemimpinan otoriter (semuanya serba bergantung pemimpin), (2) kepemimpinan leizess-faire (semuanya bergantung pada bawahan/masa bodoh), kepemimpinan demokratis (kerjasama pemimpin dengan bawahan), (4) kepemimpinan pseudodemokratis (tampaknya demokratis, tetapi hakikatnya otoriter atau demi kepentingan kelompok kecil, semu, manipulatif). Jenis kepemimpinan lainnya yang diterapkan oleh kedua ketua pada masing-masing situs yaitu tipe kepemimpinan demokratis, seperti yang terdapat dalam penjelasan di atas. Penerapan tipe kepemimpinan demokratif lebih spesifik dilakukan pada saat rapat yang melibatkan para anggota untuk menyampaikan gagasan, pendapat, dan masukan.

Menurut Faturahman (2018) kepemimpinan merupakan faktor utama dalam pencapaian tujuan sebuah organiasi. Namun, dalam usaha pencapaian tujuan tersebut tetap memperhatikan perilaku para bawahan dimana perilaku tersebut membentuk sebuah budaya dalam organisasi. Perilaku para bawahan tersebut sebagai pertimbangan oleh pemimpinan untuk mengambil keputusan. Dalam pelibatan anggota untuk mewujudkan tujuan organisasi, Ketua Sekolah Tinggi Agama Buddha memberikan kewenangan kepada Wakil Ketuanya untuk menjalankan kegiatan operasional. Menurut Robbin (2006) kepemimpinan merupakan kemampuan memotivasi karyawan, mengatur aktivitas individu lain, memilih saluran komunikasi yang paling efektif, atau menyelesaikan konflik di antara anggotanya. Pada situs I, Bhikkhu Subhapañño menerapkan prinsip yaitu menempatkan orang yang tepat, the right man on the right place yang memberikan dampak secara tidak langsung yaitu wakil ketua begitu dominan. Sementara itu, dalam situs II, Bhante Ditthisampanno yang keberadaannya masih menempuh studi doktoralnya di Thailand, menyebabkan inisiatif, tanggung jawab dan kontribusi lebih banyak muncul dari para anggota daripada Ketua sehingga tanpa keberadaan Bhante Ditthi di STIAB Smaratungga tidaklah memberikan dampak signifikan karena pekerjaan internal STIAB Smaratungga lebih banyak dijalankan oleh Wakil Ketua I. Hal tersebut juga memberikan dampak yaitu motivasi kerja dari para staf pada masa-masa awal Bhante Ditthi menjabat sebagai Ketua STIAB Smaratungga.

Menurut Robbin (2006) kepemimpinan merupakan kemampuan untuk memengaruhi kelompok menuju pencapaian sasaran. Cara Ketua Sekolah Tinggi Agama Buddha dalam menanamkan pengaruh kepada para anggotanya dapat dilihat dari status yang disandang oleh ketua yaitu sosok bhikkhu yang merupakan rohaniawan Buddhis dan kharismatik. Hal tersebut secara otomatis membuat anggota bersikap hormat. Kepemimpinan karismatik dapat terjadi ketika seorang manajer atau pemimpin dalam suatu organisasi memperoleh pengikut yang berdedikasi, bukan hanya karena posisi formal, tetapi karena ia dipandang sebagai sosok yang luar biasa, yang berbakat, dan orang yang dapat memberikan inspirasi (Levay, 2010). (Smith et al., 2018) memaparkan salah satu gaya kepemimpinan yang memungkinkan para pemimpin untuk memanfaatkan berbagai pendekatan untuk memengaruhi orang lain hasil positif dan manusiawi adalah kepemimpinan spiritual. Menurut Thompson, (2012) gaya kepemimpinan spiritual, mewujudkan nilai dan menggunakannya untuk membangun kerja sama dan dukungan di antara semua pemangku kepentingan. Menurut Low \& Ayoko (2020) Otoritas 'mewakili kekuatan atau "substansi" yang mendukung kata dan tindakan para pemimpin spiritual dan menyebabkan pengikut untuk mengikuti mereka. Otoritas dikembangkan melalui pengalaman spiritual pemimpin yang melibatkan hubungan yang mendalam/keyakinan dengan makhluk yang lebih tinggi. Dalam hal spiritualitas, menurut Boorom (2009) bahwa spiritualitas dan penerapannya pada budaya kerja adalah masalah yang menarik bagi praktisi manajemen dan akademisi karena penelitian kontemporer telah menyarankan bahwa domain spiritual adalah elemen integral dari kepemimpinan. Di dalam Agama Buddha, bhikkhu merupakan sebutan guru spiritual yang mempraktikkan kehidupan suci (hidup selibat) sesuai dhamma vinaya (ajaran dan 227 peraturan) yang telah ditetapkan oleh Buddha. Menurut Morrill (2010) pemimpin adalah individu khusus yang ditandai oleh atribut dan kemampuan, seperti tekad tinggi, energi, kecerdasan, kemampuan persuai, dan kepribadian yang kuat yang biasa disebut dengan kharisma. 
Di satu sisi, para anggota yang berada di lembaga STAB pada kedua situs yaitu para perumahtangga yang melaksanakan lima peraturan moralitas Buddhis. Menurut Priyadarshana (2018) moralitas dan spiritualitas adalah karakteristik dan persyaratan terpenting bagi masyarakat dan sifat tersebut terdapat dalam agama. Dari perbedaan aspek peraturan moralitas yang dijalankan itu, memberikan dampak pada munculnya rasa hormat kepada Ketua Sekolah Tinggi Agama Buddha. Hal lainnya yang dapat ditemukan pada kedua situs penelitian tentang cara menanamkan pengaruh kepada anggotanya yaitu dengan melakukan pendekatan yang humanis, sifat Ketua yang low profile serta budaya kekeluargaan yang telah terbangun dalam lingkungan lembaga pendidikan tinggi di kedua situs tersebut. Chandra (2005) mengemukakan bahwa terdapat keahlian tertentu yang perlu dimiliki seorang pemimpin yang pandai, yaitu kewibawaan sangat penting bagi seorang pemimpin. Pemimpin yang tidak berwibawa tidak akan diacuhkan oleh bawahannya. Kewibawaan muncul bukan karena bawahan merasa takut, tetapi karena dihormati oleh bawahan. Penghormatan muncul karena adanya integritas, kesungguhan, kharisma. Ia dapat bersikap tegas tanpa mempermalukan siapapun. Menurut House dalam (dalam Yukl, 2015) pemimpin kharismatik membuat para pengikut merasa bahwa keyakinan pemimpin adalah benar, bawahan dengan sukarela bersedia mematuhi pemimpin, bawahan merasakan kasih sayang, serta secara emosional terlibat dalam misi grup atau organisasi.

\section{Prinsip Kepemimpinan Bhikkhu di Lembaga Pendidikan Agama Buddha}

Pada fokus prinsip kepemimpinan bhikkhu di lembaga pendidikan agama Buddha dijabarkan menjadi tiga komponen, yaitu prinsip kepemimpinan bhikkhu dalam membangun komunikasi, prinsip kepemimpinan bhikkhu dalam penerapan kepemimpinan yang efektif dan efisien, prinsip kepemimpinan bhikkhu dalam penyelesaian masalah.

Menurut Robbin (2006) kepemimpinan merupakan kemampuan memotivasi karyawan, mengatur aktivitas individu lain, memilih saluran komunikasi yang paling efektif, atau menyelesaikan konflik di antara anggotanya. Prinsip membangun komunikasi yang dilakukan oleh kedua ketua pada masing-masing situs memiliki kesamaan yaitu dengan menggunakan teknologi komunikasi kekinian (smartphone) yang didalamnya terdapat aplikasi komunikasi yaitu whatsapp untuk chat dan email untuk surat menyurat. Seperti yang telah diketahui sebelumnya bahwa keberadaan ketua masing-masing situs tidak selalu berada di tempat, maka yang menjembatani komunikasi jarak jauh menggunakan smartphone. Kecepatan memberikan respons, jawaban, dan tanggapan tergantung dari kelonggaran waktu yang dimiliki oleh masing-masing ketua, sedangkan dalam hal pola komunikasi, dapat dilakukan secara formal dan non-formal tergantung dari situasi yang terjadi. Buddha berkotbah: "Seorang Bhikkhu yang mengendalikan lidahnya yang berbicara dengan bijaksana dan tidak sombong yang dapat menerangkan Dhamma beserta artinya, maka akan kedengaran indah ucapannya" seperti yang dituliskan oleh (Rajavaracariya, 2013). Alur komunikasi bukan hanya berjalan vertikal, tetapi juga horizontal dan diagonal. Hal tersebut dapat terjadi karena adanya budaya kekeluargaan yang terbentuk dalam lingkungan di kedua situs. Dalam pembawaan sikap berbicara, dilakukan dengan santai, tidak kaku, tetapi tetap masih memberikan hormat kepada ketua.

Penerapan kepemimpinan yang efektif dan efisien. Pemimpin harus menerapkan usaha benar dan pandai mengambil keputusan dan menyiapkan calon pengganti yang tepat. Menurut Imron (2017) pemimpin yang baik adalah yang menjaga keseimbangan antara orientasi tugas dan orientasi hubungan dengan orang (bawahan, stakeholders). Pemimpin yang ideal adalah yang dapat memenuhi tuntutan-tuntutan institusionalnya, tetapi juga dapat memenuhi harapan, kebutuhan dan aspirasi bawahannya. Semua ini sesuai dengan fungsi kepemimpinan ialah fungsi yang terkait dengan pancapaian tujuan, dan fungsi yang terkait dengan menciptakan iklim yang sehat dan menyenangkan untuk bawahan. Fahmi et al., (2018) memaparkan bahwa kepemimpinan mempunyai peranan sentral dalam kehidupan organisasi maupun kelompok. Untuk mencapai tujuan bersama, manusia di dalam organisasi perlu membina kebersamaan dengan mengikuti pengendalian dari pemimpinnya. Dengan pengendalian tersebut, perbedaan keinginan, kehendak, kemauan, perasaan, kebutuhan dan lain-lain dipertemukan untuk digerakkan ke arah yang sama. Dengan demikian, berarti di dalam setiap organisasi perbedaan individual dimanfaatkan untuk mencapai tujuan yang sama sebagai kegiatan kepemimpinan. Pada prinsipnya, kedua ketua pada masing-masing situs menerapkan perilaku kepemimpinan delegasi yang begitu dominan sehingga mengharuskan untuk memberikan wewenang dan tanggung jawab pelaksanaan kegiatan operasional lembaga kepada wakil ketua. Dengan penerapan delegasi ini, maka fungsi ketua lebih banyak melakukan kontrol pada masing-masing lembaga. Fungsi controlling yang dimaksud agar ketua dapat memberikan pertimbangan-pertimbangan sebelum mengambil keputusan.

Struktur dan budaya kepemimpinan yang baik harus dibangun dalam konteks tempat kerja tertentu untuk mengatasi potensi konflik (Hicks, 2002). Pemimpin harus pandai menemukan masalah dan sumber masalah sehingga dapat menentukan akhir masalah dan cara penyelesaiannya. Menurut Chen \& Chen (2018) pengambilan keputusan mengacu pada komitmen manajerial ketika mengalokasikan dan mendistribusikan sumber daya organisasi untuk menyelesaikan masalah. Pada dasarnya, ini adalah kegiatan yang melibatkan penilaian berdasarkan informasi yang telah dikelompokan dan bergantung pada identifikasi hubungan antara faktor lingkungan organisasi dan variabel keputusan. Pemimpin harus pandai menganalisa masalah dengan informasi dari berbagai sumber yang jujur dan mencari penyelesaian yang optimal. Prinsip kepemimpinan bhikkhu dalam penyelesaian masalah yaitu bersikap hati-hati dan bijak serta to the point dengan masalah yang terjadi. Menurut Burns (1978) dalam (Davenport, 2015) menyatakan bahwa empati adalah kualitas kepemimpinan yang vital untuk memasuki perasaan dan 
perspektif orang lain. Hal itu merupakan awal dari moral kepemimpinan. Tradisi Buddhis telah memberi seperangkat praktik untuk mengetahui sifat dasar pikiran. Untuk melakukan ini, seseorang membutuhkan pikiran yang tenang dan stabil (Bush, 2011). Dalam proses pemecahan masalah, jika masalah tersebut terjadi secara perseorangan, maka ketua memanggil secara personal untuk mengetahui permasalahan yang terjadi. Namun, jika suatu masalah terjadi bukan berkaitan dengan personal tertentu, maka masalah tersebut diselesaikan dalam rapat untuk mendapatkan pemecahan masalah yang diputuskan bersamasama. Menurut Byham \& Wellins (2017) alasan untuk menyelenggarakan rapat yaitu untuk mengidentifikasikan masalah dan peluang, serta bagaimana cara terbaik menangganinya. Membuat keputusan dan mencari masukan. Menyelesaikan proyek atau tugas sehari-hari yang memerlukan koordinasi dan komunikasi di antara angggota tim. Ketua pada kedua situs juga memberikan kewenangan kepada wakil ketua untuk mengambil sebuah keputusan apabila masalah tersebut bisa diselesaikan oleh wakil ketua dan ketua menerima laporan dari penyelesaian masalah tersebut.

\section{SIMPULAN}

Berdasarkan paparan hasil temuan penelitian yang telah disajikan mbenurut jabaran fokus, maka simpulan penelitian dirumuskan sebagai berikut. Pertama, nilai religius yang menjiwai kepemimpinan bhikkhu di lembaga pendidikan agama Buddha yaitu kepemimpinan bhikkhu di lembaga pendidikan agama Buddha terdapat faktor internal dan eksternal yang mendorong bhikkhu menjadi ketua sekolah tinggi agama Buddha. Dorongan internal yaitu pengalaman sebagai pemimpin dan dorongan untuk mengabdi, serta memenuhi syarat kualifikasi akademik, sedangkan dorongan eksternal pada dasarnya ditunjuk oleh yayasan untuk menjadi ketua. Nilai religius dalam kepemimpinan bhikkhu di lembaga pendidikan tinggi agama Buddha yaitu nilai yang termuat dalam dasa raja dhamma yang dalam pelaksanaannya ditunjang oleh pengendalian diri sesuai dhamma vinaya dan pelaksanaan meditasi. Kedua, jenis kepemimpinan bhikkhu di lembaga pendidikan tinggi agama Buddha mixs (campuran), yaitu tipe kepemimpinan demokratis, perilaku kepemipinan delegasi, dan partisipatif yang memberikan dampak pada lemah di bagian kontrol dan sulit dalam mengambil keputusan. Cara ketua perguruan tinggi dalam melibatkan anggota untuk mencapai tujuan organisasi yaitu dengan melakukan penempatan orang yang tepat, memberikan peran besar wakil ketua dan partisipasi aktif anggota. Sosok personal sebagai bhikkhu yang merupakan rohaniawan buddhis dan menggunakan pendekatan humanistik, serta unsur kekeluargaan dalam budaya kerja dapat menanamkan pengaruh kepada para anggota. Ketiga, prinsip kepemimpinan bhikkhu di lembaga pendidikan agama Buddha di Sekolah Tinggi Agama Buddha yaitu penggunaan alat komunikasi oleh Ketua Sekolah Tinggi Agama Buddha ketika tidak berada di tempat, mudah dihubungi serta pola komuikasi formal dan non formal tergantung dari situasi. Adanya kontrol oleh ketua, memotivasi dari jauh, serta memberikan wewenang kepada wakil ketua. Pengambilan keputusan yang cepat dan rapat untuk menyelasaikan masalah sebagai cara untuk penerapan kepemimpinan yang efektif dan efisien. Cara penyelesaian masalah yang dilakukan oleh ketua yaitu mengambil sikap hati-hati dan tidak memihak, melakukan pendekatan personal dengan menerima masukan dari berbagai pihak.

Berdasarkan pada simpulan penelitian yang telah dipaparkan di atas, maka saran yang dapat disampaikan adalah sebagai berikut. Pertama, Yayasan Dhammadipa Arama dan Yayasan Buddhayana Semarang, hasil penelitian ini dapat dijadikan rujukan dan bahan pertimbangan dalam memilih dan menentukan sosok bhikkhu untuk menjadi Ketua di Sekolah Tinggi Agama Buddha di bawah naungan yayasannya masing-masing. Kriteria sosok bhikkhu yang dipilih berkaitan dengan dorongan bhikkhu menjadi ketua STAB, dan nilai-nilai religius yang menjiwai kepemimpinan bhikkhu. Penerapan jenis kepemimpinan bhikkhu, pelibatan anggota dalam mewujudkan tujuan organisasi, serta menanamkan pengaruh terhadap anggota. Prinsip kepemimpinan bhikkhu dalam membangun komunikasi, penerapan kepemimpinan yang efektif dan efisien, dan penyelesaian masalah. Kedua, Ketua Sekolah Tinggi agama Buddha, hasil penelitian ini, ketua diharapkan dapat mempertahankan dan meningkatkan kepemimpinan religius agama Buddha yang telah diterapkan selama ini, khususnya yang berkaitan dengan implementasi nilai religius agama Buddha dalam kepemimpinan di lembaga pendidikan tinggi masing-masing, jenis kepemimpinan bhikkhu tentang pelibatan anggota dan cara untuk menanamkan pengaruh kepada anggota, prinsip-prinsip kepemimpinan bhikkhu dalam membangun komunikasi, kepemimpinan yang efektif dan efisien serta dalam penyelesaian masalah sehingga mampu meningkatkan kinerja kelompok agar lembaga yang dikelola menjadi dikenal, diminati dan dipilih oleh masyarakat Buddha secara luas. Oleh karena itu, Ketua Sekolah Tinggi Agama Buddha disarankan untuk senantiasa mengasah kompetensi diri dan kualitas perkembangan batin secara terus menerus yang berkesinambungan (continuous improvement). Ketiga, bagi tenaga kependidikan disarankan untuk meningkatkan kompetensi diri sehingga dapat mendukung Ketua Sekolah Tinggi Agama Buddha dalam menjalankan kegiatan operasional dalam lembaga tersebut dengan baik sesuai dengan nilai-nilai religius agama Buddha. Keempat, peneliti lain, hasil penelitian ini dapat ditindaklanjuti oleh peneliti lain dengan mengembangkan tiga alternatif penelitian, yaitu (a) menggunakan fokus penelitian sama namun dilakukan pada situs yang berbeda, (b) menggunakan fokus yang sama, namun rancangan dan teknik analisis yang berbeda, dan (c) menggunakan fokus lain yang relevan dan berkelanjutan. 


\section{D,AFTAR RUJUKAN}

Beckford, J. A. (2015). Religious Organizations. In International Encyclopedia of the Social \& Behavioral Sciences: Second Edition (Second Edition, Vol. 20). Elsevier. https://doi.org/10.1016/B978-0-08-097086-8.84044-1

Boorom, R. (2009). Spiritual Leadership: A Study of the Relationship between Spiritual Leadership Theory and Transformational Leadership. ProQuest Dissertations and Theses, May, 174.

Brooks, J. S., \& Normore, A. H. (2010). Educational Leadership and Globalization: Literacy for a Glocal Perspective. Educational Policy, 24(1), 52-82. https://doi.org/10.1177/0895904809354070

Bush, M. (2011). Mindfulness in Higher Education. Contemporary Buddhism, 12(1), 183-197. https://doi.org/10.1080/14639947.2011.564838

Byham, T. M., \& Wellins, R. S. (2017). Your First Leadership Job. Penerbit Buku Kompas.

Chandra, A. (2005). Bagaimana Seyogyanya Pemimpin Buddhis itu? Majalah Wandani, 19-20.

Chen, M. S., \& Chen, P. Y. (2018). Incorporating the Buddha'S Threefold Training with Management Science Theories. Contemporary Buddhism, 19(2), 203-222. https://doi.org/10.1080/14639947.2018.1573851

Crosby, K., Mai, C., \& Books, S. (2014). How Theravada is Theravada? Exploring Buddhist identities. 209, $2008-2011$.

Davenport, B. (2015). Compassion, Suffering and Servant-Leadership: Combining Compassion and Servant-Leadership to Respond to Suffering. Leadership, 11(3), 300-315. https://doi.org/10.1177/1742715014532481

Fahmi, M., Agung, S., \& Rachmatullaily, R. (2018). Gaya Kepemimpinan dan Budaya Organisasi terhadap Kinerja Karyawan. INOVATOR: Jurnal Manajemen, 7(1), 90-109. https://doi.org/10.32832/inovator.v7i1.1462

Faturahman, B. M. (2018). Kepemimpinan dalam Budaya Organisasi. MADANI: Jurnal Politik dan Sosial Kemasyarakatan, $10(1), 1-11$.

Fry, L., \& Niciewitz, M. (2013). Maximizing the Triple Bottom Line Through Spiritual Leadership. Stanford University Press.

Gieseke, A. R. (2014). The Relationship between Spiritual Intelligence, Mindfulness, and Transformational Leadership among Public Higher Education Leaders (Doctoral dissertation). ProQuest Dissertations and Theses, February, 169.

Hartog, Deanne N. Den \& Koopman, P. L. (2001). Organizational Psychology Leadership in Organizations. In Handbook of Industrial, Work \& Organizational Psychology (Vol. 2). SAGE Publications Ltd.

Hicks, D. A. (2002). Spiritual and Religious Diversity in the Workplace. Implications for Leadership. Leadership Quarterly, 13(4), 379-396. https://doi.org/10.1016/S1048-9843(02)00124-8

Imron, A. (2017). Proses Manajemen Tingkat Satuan Pendidikan. Jakarta: Bumi Aksara.

Kaplan, U. (2016). Updating the Vinaya: Formulating Buddhist Monastic Laws and Pure Rules in Contemporary Korea. Contemporary Buddhism, 17(2), 252-274. https://doi.org/10.1080/14639947.2016.1234753

Levay, C. (2010). Charismatic Leadership in Resistance to Change. Leadership Quarterly, 21(1), 127-143. https://doi.org/10.1016/j.leaqua.2009.10.010

Low, J. J. Q., \& Ayoko, O. B. (2020). The Emergence of Spiritual Leader and Leadership in Religion-Based Organizations. Journal of Business Ethics, 161(3), 513-530. https://doi.org/10.1007/s10551-018-3954-7

McKenzie, R. A. (2014). A Correlational Study of Servant Leadership and Teacher Job Satisfaction in a Public Education Institution. Dissertation Abstracts International Section A: Humanities and Social Sciences, 74(7-A(E)), No-Specified. https://doi.org/UMI Number: 3537800

Miles, M. B., Huberman, A. M., \& Saldana, J. (2014). Qualitative Data Analysis: A Method Sourcebook (Third Edition). SAGE Publication, Inc.

Moleong, L. J. (2014). Metode Penelitian Kualitatif Edisi Revisi. Bandung: PT. Remaja Rosdakarya.

Morrill, R. L. (2010). Strategic Leadership Integrating Strategy and Leadership in Colleges and Universities. Rowman \& Littlefield Publishers, Inc.

Nyanissara. (2008). Buddhist Sangha and Social Welfare. Buddhism \& Ethics, 514-516.

Phipps, K. A. (2012). Spirituality and Strategic Leadership: The Influence of Spiritual Beliefs on Strategic Decision Making. Journal of Business Ethics, 106(2), 177-189. https://doi.org/10.1007/s10551-011-0988-5

Priyadarshana, G. S. C. (2018). The Utility of Buddhist Perspective as A Conflict Solution for Religious Terrorism in Modern World. $5^{\text {th }}$ International Conference 2018, International Association of Theravada Buddhist Universities.

Rajavaracariya. (2013). Dhammapada. Bahussuta Society.

Riduwan (Ed.). (2011). Manajemen Pendidikan. Bandung: Alfabeta.

Robbin, S. P. (2006). Perilaku Organisasi. Jakarta: PT Indeks.

Rohmat. (2010). Kepemimpinan Pendidikan; Konsep dan Aplikasi. STAIN Press.

Smith, G., Minor, M., \& Brashen, H. (2018). Spiritual Leadership: A Guide to a Leadership Style That Embraces Multiple Perspectives. Journal of Instructional Research, 7(1), 80-89. https://doi.org/10.9743/jir.2018.7

Thompson, S. (2012). Hidden Strength: Encouraging Spiritual Leadership Attributes Among School Leaders. Journal of Excellence in College Teaching and Learning, 10(November), 107-118. 
1012 Jurnal Pendidikan, Vol. 5, No. 7, Bln Juli, Thn 2020, Hal 1003-1012

Visuddhangkoon, D. (2018). The Dhammic Methaphor: Reflections on the Teaching of Ajahn Chah. $5^{\text {th }}$ International Conference 2018, International Association of Theravada Buddhist Universities.

Widya, D. K. 2010. (2010). Penuntun Berorganisasi. DPD Patria.

Yukl, G. (2015). Kepemimpinan dalam Organisasi (Leadership in Organization). Edisi Ketujuh. Indeks.

Zacher, H., Pearce, L. K., Rooney, D., \& McKenna, B. (2014). Leaders' Personal Wisdom and Leader-Member Exchange Quality: The Role of Individualized Consideration. Journal of Business Ethics, 121(2), 171-187. https://doi.org/10.1007/s10551-013-1692-4 